\title{
Effects of Feeding on Respiratory Mechanics of Healthy Newborn Infants
}

\author{
GEORGE RUSSELL and ELIZABETH A. FEATHER \\ From the Department of Child Health, University of Aberdeen, and Aberdeen Maternity Hospital \\ Russell, G., and Feather, E. A. (1970). Archives of Disease in Childhood, 45, \\ 325. Effects of feeding on respiratory mechanics of healthy newborn infants. \\ Methods for the study of respiratory mechanics of the newborn infant are described. \\ In 20 healthy neonates, small feeds had no adverse effect on respiratory mechanics.
}

In previous studies of the respiratory mechanics of newborn infants no attempt has been made to relate the results to feeding, though Barrie (1968) has described increased intra-oesophageal pressure swings following tube-feeding. In the present paper a technique for the study of neonatal respiratory mechanics is described, and the effects of feeding on the respiratory work and pulmonary compliance of 20 healthy newborn infants are reported.

\section{Materials and Methods}

Infants studied. 20 apparently healthy infants born in Aberdeen Maternity Hospital were studied. All weighed over $2500 \mathrm{~g}$. at birth. Further data are presented in Table I.

\section{TABLE I}

The 20 Babies and Their Feeds

\begin{tabular}{l|c|c}
\hline & Mean & SE \\
\hline Birthweight (g.) & 3107 & 71 \\
Age when studied (hr.) & $43 \cdot 6$ & $3 \cdot 8$ \\
Volume of feed (ml.) & $38 \cdot 5$ & $4 \cdot 1$ \\
Volume of feed (ml./kg.) & $12 \cdot 4$ & $1 \cdot 3$ \\
Time between studies (min.) & $14 \cdot 4$ & $2 \cdot 0$ \\
\hline
\end{tabular}

Tidal volume measurements. A pneumotachygraph* was connected to the infant by means of an acrylic coupler with vinyl $\dagger$ nose pieces, fixed in position by non-irritant adhesive tape+ (Fig.). The pneumotachygraph had a screen area of 0.28 sq. $\mathrm{cm}$., an internal volume of $1.5 \mathrm{ml}$, and gave linear recordings up to

Received 14 November 1969.

${ }^{\star}$ F2, $6 \mathrm{~mm}$ flow-head, Mercury Electronics Ltd.

†Portex ivory vinyl, Portland Plastics Ltd.

$\neq$ Dermicel surgical tape, Band-aids; Cleartape, Johnson and Johnson.
$121 . / \mathrm{min}$., well in excess of the peak flows recorded in neonates by Swyer, Reiman, and Wright (1960). The internal volumes of the couplers varied between $0.7 \mathrm{ml}$. and $1 \mathrm{ml}$. The pneumotachygraph was attached to a defocusing differential pressure transducer, ${ }^{\star}$ the output from which was integrated electronically, $t$ and the resulting signal, proportional to volume, was displayed on a polygraph. $\ddagger$

Oesophageal pressure measurement. A $3 \mathrm{~cm}$. long air-filled balloon $\S$ with a circumference of $1.5 \mathrm{~cm}$. was attached to a $5 \mathrm{f}$.g. vinyl feeding-tube at the end of which additional side openings had been cut. This was passed by mouth into the oesophagus and connected to a defocusing pressure transducer $\uparrow$ whose output was displayed on the polygraph.

Calibration procedure. Before and after each study, the response characteristics and linearity of the two pressure recording systems were compared. Usually the response times were identical, $95 \%$ of the response to a square wave pressure change occurring in $0.09 \mathrm{sec}$., and the inclusion of the integrator in the circuit had no measurable effect on the response time. Occasionally the balloon delayed the response of the oesophageal pressure channel, and when this delay amounted to more than 0.01 sec., the record was discounted. Allowance was made for shorter delays in the analysis of the tracings. Both systems invariably gave linear responses to volume and pressure changes.

Compliance and work of breathing. Pulmonary compliance was calculated from 10 consecutive breaths by the method of von Neergaard and Wirz (1927). Respiratory rate, mean tidal volume, and minute volume were calculated from the same 10 breaths. A represen-

$\star$ Greer micromanometer, capsule A10, Mercury Electronics Ltd. †Integrator supplied by Devices Sales Ltd.

$¥$ M8 recorder, Devices Sales Ltd.

\$ Jesophageal balloon, Dunlop Rubber Co. Ltd.

TGreer micromanometer, capsule A 1000, Mercury Electronics. 


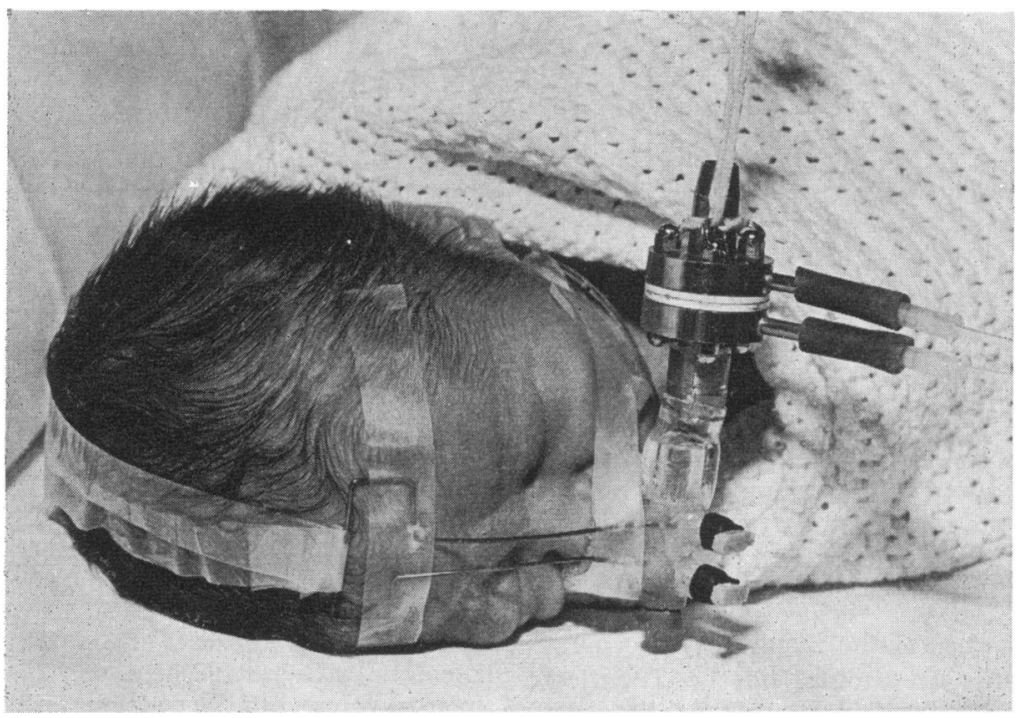

Fig.-The nasal adaptor has openings opposite the nares through which the nostrils may be aspirated, and it can be opened at either end to allow the coupling of apparatus such as the pneumotachygraph shown here. With the spigots removed from all these openings, air has free entry to the adaptor and dead space effect is negligible.

tative breath was selected, a volume-pressure loop constructed, and total and viscous work were measured by planimetry as described by Otis, Fenn, and Rahn (1950). The length of the breath so analysed was measured, and rates of work were based on the respiratory frequency derived from this figure which was not used for any other purpose. Total work per minute measured in this way was compared with values calculated using McIlroy's formula (Cook et al., 1957).

The design of the Greer micromanometer (Greer, 1958) is such that it is impossible to subtract the pressure drop across the pneumotachygraph from the measured oesophageal pressure: this has no effect on compliance measurements but introduces a small amount of additional viscous work; this has not been allowed for in the calculations as the error is slight and is in any case present both before and after feeding.

Study procedure. The coupling device and the oesophageal balloon were secured in position and the infant was bottle-fed. He was then returned to his cot, the pneumotachygraph was attached, and tracings of tidal volume and oesophageal pressure obtained and scrutinized for technical errors or artefacts. The pneumotachygraph was then removed and the infant left undisturbed until signs of hunger appeared. With the infant on his right side, the pneumotachygraph was again attached and further recordings were made (prefeed study). With the coupler but not the pneumotachygraph in situ, the infant was picked up and given the feed prescribed by the paediatrician on the ward. The infant was then returned to the cot, placed on his right side, and further pressure-volume recordings made (post-feed study). The interval between the pre- and post-feed studies ranged from 5 to 35 minutes (see Table I).

Statistical analysis. The Student $t$ test for pairs $\overrightarrow{\vec{D}}$ was used to evaluate the differences between the results 3 of the pre-feed and post-feed studies, the differences being expressed both as absolute numbers and as percentage changes.

\section{Results}

A comparison of the results of the pre-feed and post-feed studies is presented in Table II. Feeding had no significant effect on any of the factors measured. Work measured by planimetry correlated well with work measured by McIlroy's formula $(r=0.98 ; p<0.00001)$.

\section{Discussion}

The work of breathing measured in the present $N$ study is similar to that reported elsewhere (McIlroy and Tomlinson, 1955; Cook et al., 1957; Swyer et al., 1960). The compliance figures are similar to those reported for other healthy infants (Cook et al., 1957; Geubelle et al., 1959; Swyer et al., of 1960; Karlberg and Koch, 1962; Drorbaugh et al., 1963; Chu et al., 1964; Polgar and String, 1966), though higher than compliances derived from the data of McIlroy and Tomlinson (1955) and higher 
TABLE II

Effects of Feeding on Respiratory Mechanics in 20 Babies

\begin{tabular}{|c|c|c|c|c|c|c|c|c|}
\hline & $\begin{array}{c}\text { Mean } \\
\text { Pre-feed } \\
\text { (A) }\end{array}$ & $\begin{array}{c}\text { Mean } \\
\text { Post-feed } \\
\text { (P) }\end{array}$ & $\begin{array}{l}\text { Mean } \\
\text { Change } \\
(\mathrm{A}-\mathrm{P})\end{array}$ & $\begin{array}{c}S E \\
\text { of } \\
A-P\end{array}$ & $\mathbf{p}$ & $\begin{array}{l}\text { Mean \% } \\
\text { Change } \\
\frac{\mathrm{A}-\mathrm{P}}{\mathrm{A}} \%\end{array}$ & $\frac{\begin{array}{c}\mathrm{SE} \\
\text { of } \\
\mathrm{A}-\mathrm{P}\end{array}}{\mathrm{A}} \%$ & $\mathbf{p}$ \\
\hline $\begin{array}{l}\text { Total work per breath }(\mathrm{g} . \mathrm{cm} .) \\
\text { Total work per minute }(\mathrm{g} . \mathrm{cm} .) \\
\text { Viscous work per breath }(\mathrm{g} . \mathrm{cm} .) \\
\text { Viscous work per minute }(\mathrm{g} . \mathrm{cm} .) \\
\text { Respiratory rate (per minute) } \\
\text { Minute volume (ml.) } \\
\left.\text { Pulmonary compliance (ml./cm. } \mathrm{H}_{2} \mathrm{O}\right)\end{array}$ & $\begin{array}{l}53 \cdot 95 \\
2766 \\
47 \cdot 10 \\
2396 \\
56 \cdot 65 \\
741 \\
4 \cdot 825\end{array}$ & $\begin{array}{l}41 \cdot 25 \\
3308 \\
34 \cdot 05 \\
1953 \\
55 \cdot 65 \\
740 \\
6 \cdot 020\end{array}$ & $\begin{array}{c}12 \cdot 70 \\
458 \\
13 \cdot 05 \\
443 \\
1 \cdot 00 \\
1 \cdot 00 \\
-1 \cdot 195\end{array}$ & $\begin{array}{c}7 \cdot 67 \\
404 \\
7 \cdot 80 \\
406 \\
3 \cdot 09 \\
43 \cdot 8 \\
0 \cdot 691\end{array}$ & $\begin{array}{l}>0.1 \\
>0.2 \\
>0.1 \\
>0.2 \\
>0.7 \\
>0.9 \\
>0.05\end{array}$ & $\begin{array}{r}3 \cdot 31 \\
1 \cdot 86 \\
1 \cdot 71 \\
-4 \cdot 42 \\
-3 \cdot 28 \\
-1 \cdot 74 \\
-43 \cdot 54\end{array}$ & $\begin{array}{c}12 \cdot 31 \\
13 \cdot 27 \\
13 \cdot 88 \\
15 \cdot 44 \\
5 \cdot 43 \\
7 \cdot 00 \\
24 \cdot 44\end{array}$ & $\begin{array}{l}>0.7 \\
>0.8 \\
>0.9 \\
>0.7 \\
>0.5 \\
>0.8 \\
>0.05\end{array}$ \\
\hline
\end{tabular}

than those recorded in anaesthetized infants by Reynolds and Etsten (1966) and by Lunn (1968).

Though the feeds given in the present study were small (mean $12.4 \mathrm{ml} . / \mathrm{kg}$. given orally over 14.4 minutes), particularly when compared to those given by Barrie (1968) (60 ml. per kg. given by naso-gastric tube over 20 minutes), it is notable that feeding had no adverse effect on any of the factors measured and, though the changes were not statistically significant, there was a slight rise in compliance and a tendency for both viscous and total work to fall after feeding. Respiratory rate and minute volume were virtually unchanged. Barrie's (1968) results may be attributable to the unusually large volumes of feed given; it certainly cannot be assumed that feeding causes some degree of respiratory embarrassment in all newborn infants. It is obviously necessary for studies to be undertaken to demonstrate the point at which adverse effects appear; this may depend not only on the volume of feed relative to the size of the infant, but also on the maturity of the infant, the time taken for the feed, and the route by which it is given. The methods described above are suitable for such investigations, and no adverse effect attributable to the apparatus has been noted during or after the studies.

We are grateful to Professor R. G. Mitchell for permission to study the infants, to Dr. Gordon Hems for the provision of computer programs for the statistical analysis, and to Mr. Hammersley for the photograph. Financial support was provided by the Secretary of State for Scotland and the Cystic Fibrosis Research Foundation Trust.

\section{REFERENCES}

Barrie, H. (1968). Effect of feeding on gastric and oesophageal pressures in the newborn. Lancet, 2, 1158.

Chu, J. S., Dawson, P., Klaus, M., and Sweet, A. Y. (1964). Lung compliance and lung volume measured concurrently in normal full-term and premature infants. Pediatrics, 34, 525.

Cook, C. D., Sutherland, J. M., Segal, S., Cherry, R. B., Mead, J., McIlroy, M. B., and Smith, C. A. (1957). Studies of respiratory physiology in the newborn infant. III. Measurements of mechanics of respiration. Fournal of Clinical Investigation, 36, 440.

Drorbaugh, J. E., Segal, S., Sutherland, J. M., Oppé, T. E., Cherry, R. B., and Smith, C. A. (1963). Compliance of lung during first week of life. American fournal of Diseases of Children, $105,63$.

Geubelle, F., Karlberg, P., Koch, G., Lind, J., Wallgren, G., and Wegelius, C. (1959). L'aération du poumon chez le nouveauné. Biologia Neonatorum, 1, 169.

Greer, J. R. (1958). A sensitive defocussing photo-electric pressure transducer. Electronic Engineering, 30, 436.

Karlberg, P., and Koch, G. (1962). Respiratory studies in newborn infants. III. Development of mechanics of breathing during the first week of life. A longitudinal study. Acta Paediatrica, suppl. $135,121$.

Lunn, J. N. (1968). Measurements of compliance in apnoeic anaesthetized infants. Anaesthesia, 23, 175.

McIlroy, M. B., and Tomlinson, E. S. (1955). The mechanics of breathing in newly born babies. Thorax, 10, 58 .

von Neergaard, K., and Wirz, K. (1927). Úber eine Methode zur Messung der Lungenelastizität am lebenden Menschen, insbesondere beim Emphysem. Zeitschrift für klinische Medizin, 105, 35.

Otis, A. B., Fenn, W. O., and Rahn, H. (1950). Mechanics of breathing in man. Fournal of Applied Physiology, 2, 592.

Polgar, G., and String, S. T. (1966). The viscous resistance of the lung tissues in newborn infants. Fournal of Pediatrics, 69, 787.

Reynolds, R. N., and Etsten, B. E. (1966). Mechanics of respiration in apneic anesthetized infants. Anesthesiology, 27, 13.

Swyer, P. R., Reiman, R. C., and Wright, J. J. (1960). Ventilation and ventilatory mechanics in the newborn. Fournal of Pediatrics, 56, 612 .

Correspondence to Dr. George Russell, Department of Child Health, University Medical Buildings, Foresterhill, Aberdeen, AB9 2ZD, Scotland. 